\title{
Preparation of spatial distribution maps of saffron water requirement in Kermanshah province.
}

\author{
Sahar Binesh ${ }^{1 *}$, Hedieh Ahmadpari ${ }^{2}$, Elham Shayegh ${ }^{3}$, Mina Masoumi $^{4}$, Farzaneh Vakili tajareh ${ }^{5}$ \\ 1-M.Sc. Graduate of Agronomy, College of Aburaihan, University of Tehran, Iran \\ sahar.binesh@ut.ac.ir \\ 2-M.Sc. Graduate of Irrigation and Drainage, College of Aburaihan, University of Tehran, Iran \\ h.ahmadpari@gmail.com \\ 3- M.Sc. Graduate of Combating Desertification, College of Natural Resources Engineering, \\ Isfahan University of Technology, Iran \\ Shayegh.pnu@gmail.com \\ 4- M.Sc. Graduate of Remote Sensing and GIS, Faculty of Geography, University of Tehran, Iran \\ Minamasomi23@yahoo.com \\ 5-M.Sc. Student of Watershed Engineering, University of Tehran, Iran farzaneh.vakili62@gmail.com
}

\begin{abstract}
Water is one of the most important environmental elements used for a variety of purposes such as irrigation of farms, food production, domestic, industrial and commercial uses. In Iran, agriculture is the largest consumer of water. If water is consumed properly in agriculture and water losses is minimized, its productivity will increase and conditions for sustainable agriculture will be provided. The irrigation system is designed according to the water requirements of the plants. Saffron is an important crop in Kermanshah province and we conserve water by doing research on water requirement of saffron. In this research the water requirement of saffron and the effect of efficient rainfall is studied in Kermanshah province and the amount of supplemental irrigation water was calculated. Water requirement was obtained experimentally and by multiplying crop coefficient of saffron (KC) with evapotranspiration of the reference crop (ETo). To calculate evapotranspiration of the reference crop (ETo) the Penman- Monteith FAO equation was used as the most valid method for estimating water requirement. Amount of effective rainfall was estimated by cropwat model based on USDA method. The results show that water requirement during growing season for saffron is $211.43,166.98,249.59,240.31$, 237.74, 204.27, 194.82, 250.13, 282.83, 191.21 and $184.2 \mathrm{~mm}$ for Kermanshah, Kangavar, Ravansar, Sarpol-e Zahab, Eslamabad-e-Gharb, Sonqor, Sanandaj, Khorramabad, Ilam, Hamedan and Qorveh respectively. Also, the results show that amount of effective rainfall during growing season for saffron is 138.9, 129.1, 191.5, 147.2, 166.4, 119.8, 128.1, 178.9, 208.5, 85.8 and 96.9 mm for Kermanshah, Kangavar, Ravansar, Sarpol-e Zahab, Eslamabad-e-Gharb, Sonqor, Sanandaj, Khorramabad, Ilam, Hamedan and Qorveh respectively. Moreover, the results show that irrigation requirement during growing season for saffron is 72.53, 37.88, 58.09, 93.11, 71.34, 84.47, 66.72, 71.23, 74.33, 105.41 and 87.3 $\mathrm{mm}$ for Kermanshah, Kangavar, Ravansar, Sarpol-e Zahab, Eslamabad-e-Gharb, Sonqor, Sanandaj, Khorramabad, Ilam, Hamedan and Qorveh respectively. Maps showed that the highest saffron water requirement happened in May which was 0.829-1.432 $\mathrm{mm} / \mathrm{day}$. The highest and lowest water requirement of saffron were observed for Sarpol-e Zahab and Kangavar stations, respectively.
\end{abstract}

Keywords: Saffron, Kermanshah province, Water requirement, Effective rainfall, Irrigation requirement

\section{Introduction}

Agriculture as the largest water consumer for its efficient water use requires an appropriate irrigation scheduling. For an optimum irrigation the amount of potential evapotranspiration is needed. The basis of an irrigation program is to determine the water requirement of plants. saffron (Crocus sativus L.) is one of the most expensive agricultural and medicinal plants in the world, which has a significant role in the economic and social conditions of Kermanshah province. Saffron is one of the strategic products of Kermanshah province, so determining the water requirement of saffron is very important. Many studies have been done on saffron plant in Iran. Rajabi et al (2015) estimated saffron evapotranspiration by Penman Monteith method and its water require in Isfahan province. In this study, the daily evapotranspiration value of saffron was estimated by PenmanMonteith method using 15-year meteorological data. As well as the amount of water requirements for saffron and the amount of precipitation during the growth stages were determined. The results showed that the west and southwest stations of the province did not reach the required temperature for the degree of plant day. Given that supplying the required plant temperature is the first factor for saffron growth, these stations are not suitable for saffron cultivation. The growing season of saffron is from October to May. In saffron growth period, at 
Ardestan station $528.1 \mathrm{~mm}$, the highest water requirement and Kashan station with $279 \mathrm{~mm}$, the minimum water requirement was measured. In Ardestan station with $407 \mathrm{~mm}$, the maximum annual irrigation was calculated and at Golpayegan station with $107 \mathrm{~mm}$ the minimum annual irrigation was estimated. Ebrahimipak et al (2018) evaluated the AquaCrop to simulate saffron (crocus sativus 1.) yield under different water management scenarios and zeolite amounts. In the study, 36 measured data for each parameter under irrigation level treatments $\left(\mathrm{I}_{1}\right.$ : traditional irrigation, $\mathrm{I}_{2}$ : deficit irrigation with $70 \%$ reduction in plant water requirement, $\mathrm{I}_{3}$ : irrigation based on the complete water requirement of the plant) and zeolite application (zero: $Z_{0}, 0.5 \%: Z_{1}, 1 \%: Z_{2}$ and $2 \%: Z_{3}$ soil weight percentage) were randomly divided into two groups. The first batch (comprising $70 \%$ of the data) was used for calibration and the second batch (comprising 30\% of the data) was used to validate the AquaCrop model. The simulation results showed that in both calibration and validation stages, the treatments with traditional irrigation had the highest difference with the measured values. In some cases, zeolite treatments reduced this difference but no significant relationship was observed between the results. The values of RMSE,

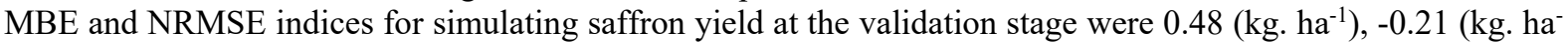
$\left.{ }^{1}\right)$ and 0.09 , respectively, and for biomass at this stage, were $151.9\left(\mathrm{~kg} . \mathrm{ha}^{-1}\right), 74.2\left(\mathrm{~kg} . \mathrm{ha}^{-1}\right)$ and 0.13 , respectively. These values showed that this model had good accuracy for simulating saffron yield and biomass. The performance of this model using EF values was optimal so that the value of this index for saffron yield in both calibration and validation stages was 0.32 and 0.42 , respectively, and for saffron biomass in these two stages were 0.99 and 0.99 , respectively. Based on the obtained results, this model has sufficient accuracy to simulate the yield and biomass of saffron under deficit irrigation and zeolite application. Therefore, using this model is suggested as an optimal model for simulating the growth and yield of saffron. Sobhani (2016) investigated the suitable area for saffron cultivation in Ardabil Province using of method AHP. This research for the study and understanding of the natural capabilities of Ardabil province for saffron cultivation using geographical information system (GIS) was implemented in 2014. Climatic data such as annual rainfall, growth period rainfall, annual temperature, growth period temperature, absolute minimum temperature and number of frost days were obtained from 14 stations in Ardabil region between the years 1988 - 2013. Slope, soil, and mean sea level were also used to determine the area suitable for saffron cultivation. By using the vegetative requirement (optimal climatic conditions) of the crop under study, the information layer was produced and each data set was evaluated and classified. In order to investigate the role of each of the climatic elements and physical factors of the earth in agro-climatic zoning by AHP method with regard to ecological need, the studied data were evaluated in GIS environment. Then, by combining all the data of climatic elements and factors together, a map of land potential for saffron planting in Ardabil province was prepared. The results showed that about $41 \%$ of Ardabil province area is suitable condition, 20\% moderate condition and 39\% unsuitable conditions for saffron planting. Aliakbari et al (2018) determined the potential and actual evapotranspiration rate and the most suitable model for estimating evapotranspiration of saffron in Torbat Heydarieh (the world's saffron producing pole). In this study, different methods of Penman- Monteith FAO, Blaney- Criddle, Hargreaves-Samani, Thorenthwaite, Jensen-Haise and Turc were evaluated. Comparison of the results obtained from Penman- Monteith FAO method with other methods was performed using chi-square test. The results of comparing the different methods with the Penman- Monteith FAO method as the standard and base method showed that Blaney- Criddle, Jensen-Haise and Hargreaves-Samani methods were more accurate than the other methods, respectively. The annual water requirement of saffron in the climate of the Torbat Heydarieh region was obtained by using the Penman- Monteith FAO method the amount of 1731 cubic meters per hectare. Since in Hargreaves-Samani equation for calculating evapotranspiration only two factors of temperature and solar radiation are needed and it is possible to determine the mentioned factors in most meteorological stations, it is suggested to use this method in early and early estimation of the saffron water requirement. Alavizadeh et al (2013) determined the suitable area for saffron cultivation in Kashmar plain using GIS. In this study, required climatic data were achieved from Khorasan Razavi Meteorological Office for the period of 1989-2012. DEM (Digital Elevation Model) topographic maps of the Surveying Organization with a scale of 1: 50000 were used to map the elevation, slope, slope direction, and TIN (Triangular Irregular Network) maps. Vegetation and land use maps were extracted from the Soil and Water Research Institute of Iran using lands capability maps with scale of 1: 50000 Geographic information system (GIS) was used for digitization and mapping. After the formation of the regional spatial database, using ArcGIS 9.3 software descriptive information was added to the maps. Then, according to the requirements circumstances of each parameter and the importance of each layer, weighting was done using AHP software (hierarchical analysis process). After weight overlap operation the zoning was done in GIS environment. The results showed the central and southern parts of the plain as the best areas for saffron cultivation. Currently, land use is allocated to rainfed cultivation, water cultivation, semi-dense and dense rangelands. Farajzadeh and Mirzabayati (2007) studied the possibility of areas with potential cultivation of saffron in Nishabor plain (in Iran) using GIS. In this study, susceptible areas of saffron cultivation were identified by using maps of elevation, slope, lands capability, soil depth, access to surface and ground water, and effective temperature thresholds for saffron cultivation in Nishabor plain in GIS environment After preparing the above maps, by using ranking, rating and AHP to weighting and integration of the maps are 
discussed. Feasibility map of saffron cultivation prone areas by combining layers in each model was prepared and finally based on the rating model as the optimal model, the final map was obtained. The results show that 2146 square $\mathrm{km}$ of plain lands have a very good potential for the development of saffron cultivation, at present, land uses is devoted to rainfed cultivation, water cultivation, semi-dense and dense pastures. By changing land use to saffron cultivation, economic development and added value can be achieved for this region. Koocheki et al (2014) investigated the effect of irrigation levels and high corm density on growth and phosphorus uptake of daughter corms of saffron. In order to study the effect of irrigation and dense cultivation on the corm behavior and phosphorus uptake in saffron, an experiment was conducted in two years 2012 and 2013 in the form of splitplot arrangement in complete randomized block design with three replications at Ferdowsi University of Mashhad, Iran. In this experiment, irrigation values $(50,75$ and $100 \%$ of saffron water requirement) as main factor and high densities including 100, 200 and $300 \mathrm{corm} / \mathrm{m}^{2}$ with control $\left(50 \mathrm{corm} / \mathrm{m}^{2}\right)$, were sub-factors, respectively. According to the results of the experiment, the lowest number of corms, yield and phosphorus content of corms were observed as a result of 50 corms per $\mathrm{m}^{2}$ and $50 \%$ irrigation, respectively, at 178,450 and $0.65 \mathrm{gm}^{-2}$, respectively. On the other hand, the highest values of mentioned indices $\left(806,2709\right.$ and $\left.3.3 \mathrm{~g} / \mathrm{m}^{2}\right)$ were obtained as a result of cultivation density of 300 daughter corms per $\mathrm{m}^{2}$ and $100 \%$ irrigation. In the first year of the experiment, $50 \%$ reduction in irrigation had no significant effect on flower number, fresh flower and dry stigma yields of saffron. However, in the second year, the reduction of irrigation up to $50 \%$ compared to the control (100\% irrigation) resulted in a significant decrease in flower number, fresh flower and dry stigma yields of saffron (up to 19, 28 and 22\%, respectively).Considering the high economic value of water consumed in arid and semi-arid regions of the country, it seems that saffron irrigation program based on $75 \%$ of the water requirement of the plant can be reasonable and justified for regions where the climate is the same as the climate where the experiment was conducted. Outside Iran, very few studies on the water requirements of saffron have also been carried out. Ahmad et al (2017) investigated the water requirement of saffron (Crocus sativus) in Kashmir valley. The results showed that the total amount of water required for saffron is $288 \mathrm{~mm}$. The amount of water needed at the initial stage was $80 \mathrm{~mm}$ (budding to flowering). This is due to the low plant canopies at this stage. The water requirement of the plant increases with increasing leaf area, plant height and canopy. So it can be said that as the vegetative growth of the plant progresses, its water requirement increases. The need for water in the middle stage of growth was $134 \mathrm{~mm}$. This constituted approximately $46 \%$ of the total water requirement of the plant. At the final stage of plant growth, the amount of water required has decreased again with a decrease in canopy cover. At this point, the leaves and roots dry up, and eventually the corms fall asleep. The amount of water needed at this stage was estimated at $74 \mathrm{~mm}$. According to the literature review, it seems that a comprehensive study on the preparation of spatial distribution maps of saffron water requirement in Kermanshah province has not been conducted. Therefore, the purpose of this study is to determine the accuracy of saffron water requirement and preparation of spatial distribution maps of saffron water requirement in Kermanshah province.

\section{Materials and methods}

The study area in this research is Kermanshah province, Iran, located 1200 meters above sea level. The average annual rainfall of the Kermanshah province is about $474.8 \mathrm{~mm}$ and in Longitude of $45^{\circ} 24^{\prime}$ east, latitude of $33^{\circ}$ 41' north is located. The center of this province is Kermanshah. Kermanshah consists of 14 counties, including Dalahu, Gilan-e Gharb, Harsin, Eslamabad-e Gharb, Javanrud, Kangavar, Kermanshah, Paveh, Qasr-e Shirin, Ravansar, Sahneh, Sarpol-e Zahab, Salas-e Babajani and Sonqor. The location of this province and its counties is shown in Figure 1. Kermanshah province has a moderate and mountainous climate. It rains most in winter and is moderately warm in summer. According to the results of the research Ghamarnia and Soltani (2016) 5082.7 $\mathrm{km}^{2}$ area of Kermanshah province suitable for cultivation of saffron. To conduct this research and calculate the reference plant evapotranspiration, monthly meteorological data including minimum temperature, maximum temperature, average temperature, minimum relative humidity, maximum relative humidity, average relative humidity, rainfall, average evaporation, mean sunny hours and average wind speed of Kermanshah province meteorological stations at the statistical years of 1994 to 2018 used. Table 1 shows the location of the meteorological stations. In this study, cropwat software has been used to calculate the evapotranspiration of the saffron plant and its water requirement. Evapotranspiration of reference plant was estimated by PenmanMonteith FAO Method and amount of effective rainfall by cropwat model based on USDA method. cropwat is a simulation model for climate, effective rainfall, crop, soil, water and irrigation requirements and irrigation scheduling (Muhammad, 2009). The cropwat simplify the calculation of the reference plant water requirement, irrigation schedule and crop water requirements with various cultivation types for irrigation planning (Muhammad, 2009). Crop coefficients (Kc) is a factor that showed the studied plant characteristics. These characteristics include leaf area, plant height, percentage of green cover and canopy resistance (Babaee et al, 2019). Table 2 shows the amount of crop coefficient in the whole period of growth (early stage, middle stage and final stage). Finally, using ArcGIS 10.5 software was prepared the spatial distribution maps for saffron water requirement in Kermanshah province. 

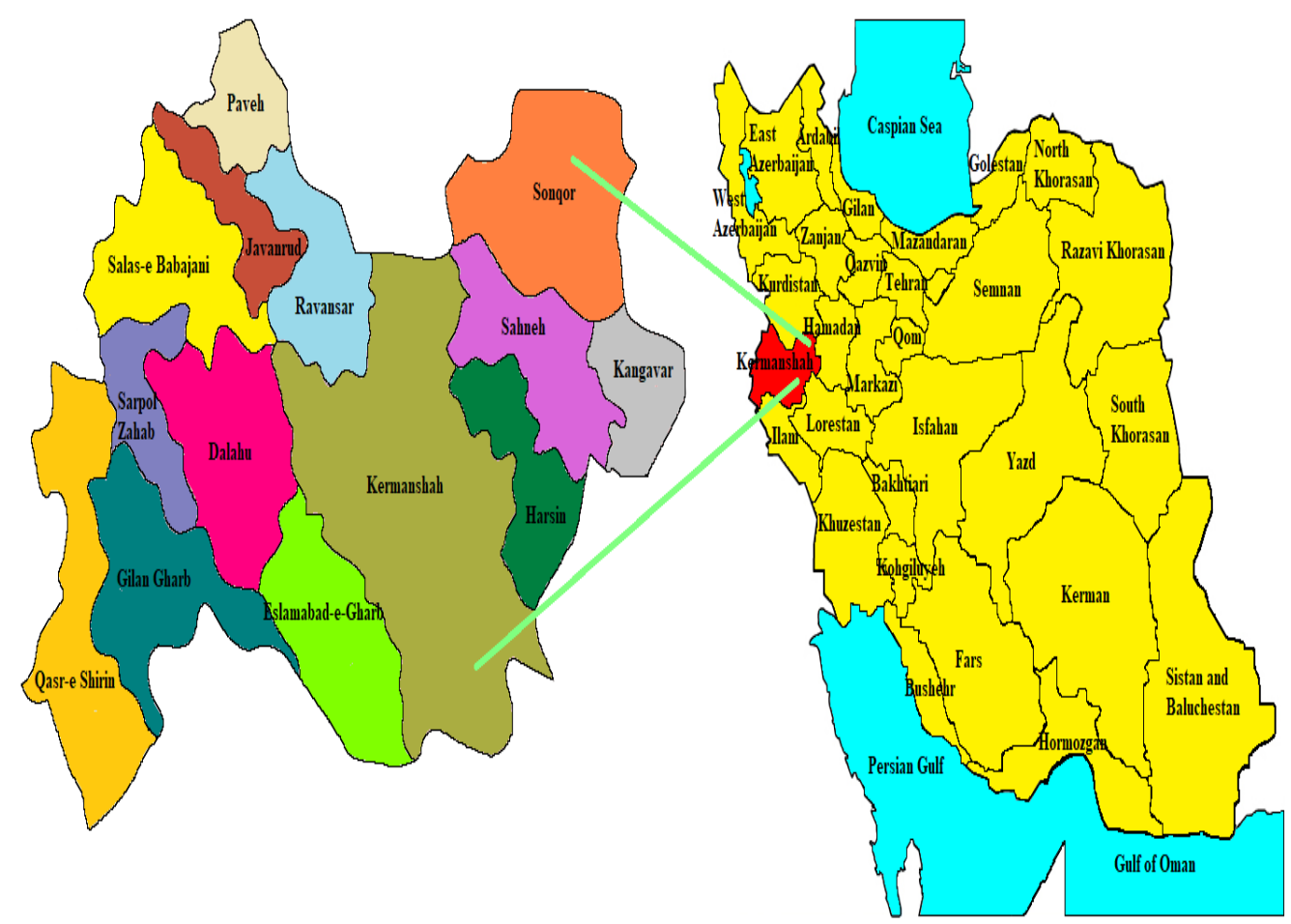

Figure 1-Location of the study area in Iran

Table 1-Specifications of Meteorological stations in the study

\begin{tabular}{|l|l|l|l|l|l|}
\hline Station name & Longitude & Latitude & $\begin{array}{l}\text { Metres above } \\
\text { sea level }\end{array}$ & UTM_X & UTM_Y \\
\hline Kermanshah & $47-9-0$ & $34-30-0$ & 1318 & 697393.72156 & 3819695.57762 \\
\hline Kangavar & $47-59-0$ & $34-30-0$ & 1468 & 773924.41713 & 3821638.83066 \\
\hline Ravansar & $46-39-0$ & $34-43-0$ & 1379 & 651089.78263 & 3842862.42939 \\
\hline Sarpol-e Zahab & $45-52-0$ & $34-27-0$ & 545 & 579611.38630 & 3812393.53782 \\
\hline Eslamabad-e-Gharb & $46-28-0$ & $34-7-0$ & 1348 & 635263.56398 & 3776063.02385 \\
\hline Sonqor & $47-35-0$ & $34-47-0$ & 1700 & 736381.33389 & 3852057.28562 \\
\hline Sanandaj & $47-0-0$ & $35-20-0$ & 1373.4 & 681772.44181 & 3911844.71626 \\
\hline Khorramabad & $48-17-0$ & $33-26-0$ & 1147.8 & 747430.6569 & 3702628.59574 \\
\hline Ilam & $46-26-0$ & $33-38-0$ & 1363 & 632936.63649 & 3722423.01960 \\
\hline Hamedan & $48-32-0$ & $34-52-0$ & 1741.5 & 774523.7415 & 3861032.74427 \\
\hline Qorveh & $47-48-0$ & $35-10-0$ & 1906 & 755019.93795 & 3895116.74770 \\
\hline
\end{tabular}

Table 2-Saffron crop coefficient during the growing season (Ahmadee et al, 2017)

\begin{tabular}{|c|c|}
\hline Month & KC \\
\hline October & 0.38 \\
\hline November & 0.46 \\
\hline December & 0.78 \\
\hline January & 0.84 \\
\hline February & 0.68 \\
\hline March & 0.50 \\
\hline April & 0.41 \\
\hline May & 0.37 \\
\hline
\end{tabular}




\section{Results and discussion}

Proper irrigation planning requires accurate calculation of the plants water requirement, and accurate calculation of the plants water requirement also requires accurate estimation of reference plant evapotranspiration values. Correct estimation of evapotranspiration values of the reference plant will enable agricultural planners make the necessary planning to supply the needed water by specifying the water requirement and the amount of effective rainfall. Table 3 shows the evapotranspiration value of the reference plant at different stations, in millimeters per month. Most of the reference plant evapotranspiration occurred in May. Temperature rise this month has increased the reference plant evapotranspiration compared to other months. The lowest reference plant evapotranspiration occurred in December and January. Temperature reduction these months has decreased the reference plant evapotranspiration compared to other months. The highest and lowest reference plant evapotranspiration values occurred at Sarpol-e Zahab and Kangavar stations, respectively. Table 4 shows the effective rainfall amount at different stations, in millimeters per month. The highest and the lowest effective rainfall were observed in Ilam and Hamedan stations, respectively, which are located outside Kermanshah province. The highest and lowest effective rainfall in Kermanshah province occurred at Ravansar and Sonqor stations, respectively. According to Table 4, it can be said that in Kermanshah province, effective rainfall plays an important role in supplying the water needed for saffron cultivation, but it is not sufficient and in order to achieve optimum yield, the plant needs irrigation during the growing season. Therefore, with this amount of effective rainfall, saffron cultivation is not feasible for economic gain and dry farming can only meet the internal needs of Kermanshah province. Therefore, in order to benefit economically from saffron cultivation in Kermanshah province, irrigation should be done to avoid drought stress. Table 5 shows the water requirement of the saffron plant at different stations, in millimeters per month. Most of the saffron plant water requirement occurred in May. Temperature rise this month has increased the saffron plant water requirement compared to other months. The lowest saffron plant water requirement occurred in December and January. Temperature reduction these months has decreased the saffron plant water requirement compared to other months. The highest and lowest amounts of saffron water requirement occur at Sarpol-e Zahab and Kangavar stations, respectively. In fact, for a product to enter the economic cycle of a region, only estimation of the effective rainfall and water requirement are not sufficient, but also a series of climatic factors (air temperature, humidity, lighting hours, etc.) and terrain (terrain slope, Topography of the area, soil texture) is also needed. Table 6 shows the irrigation requirements of saffron at different stations, in millimeters per month. The greatest irrigation requirements of saffron was observed in May. The highest irrigation requirements of saffron was observed at Hamedan station which is outside the boundary of Kermanshah province. The lowest and highest irrigation requirements of saffron in Kermanshah province were observed in Kangavar and Sarpol-e Zahab stations, respectively. Table 7 presents the sum of effective rainfall, total water requirement and saffron irrigation for all stations. The growth period of the saffron plant in Kermanshah province is at the time of autumn and winter precipitation. For this reason, farmers think that the water requirement of this plant is very low. Currently the current yield in saffron fields in Kermanshah province is unacceptable and this plant is mainly under drought stress due to deficit irrigation. Research has shown that by providing the water requirements of this plant, we can achieve high yields compared to the present situation in the fields. Karimiferezghi et al (2018) compared the effect of irrigation levels and methods on leaf area and replacement corm production of saffron. This study during 2013-2014 growing season was done in the Jolgeh Rokh District, in $35 \mathrm{~km}$ Torbat Heydarie. This research was done as split plot experiment in randomized complete block design. The main factor consisted of three irrigation methods (basin, drip and sprinkler). Also, the sub factor consisted of three irrigation levels $(100,75$ and $50 \%$ of saffron water requirement). The studied traits were containing leaf weight, leaf number, leaf diameter, leaf length, replacement corms size, replacement corms number, dry weight of replacement corms, sheath weight and sheath length. Experimental sampling was performed to determine leaf and sheath traits on April 30 and to determine corms traits on May 31, 2014. The results showed that among the irrigation method treatments, the highest increase in traits (dry weight of corm, leaf weight, sheath weight, replacement corm size, replacement corm number, leaf number, leaf diameter and leaf length) was related to drip irrigation. Also, the best yield of corms was obtained in drip irrigation method and the lowest yield of corms was observed in basin irrigation method. Drip irrigation increased the number of saffron replacement corms by $10 \%$ compared to sprinkler irrigation. Basin irrigation decreased the number of saffron replacement corms by $34 \%$ compared to drip irrigation. Investigation of the effect of irrigation levels on studied traits showed that this effect on most traits was significant. The highest yield was related to the level of irrigation is $100 \%$ and the lowest yield was related to supply level of $50 \%$ water requirement. Reduce irrigation from $100 \%$ to $50 \%$ of plant water requirement reduced the number of replacement corms and their weight by 62 and 86 percent, respectively. In total, the highest photosynthetic level of saffron and the maximum number and total weight of replacement corms were obtained in drip irrigation and at the supply level of $100 \%$ water requirement. Some studies have shown that proper selection of irrigation cut- off time can also improve the yield of saffron plant. Rezaei et al (2019) investigated the response of quantitative and qualitative characteristics of Saffron flower to the last irrigation cut-off time and various fertilizer resources. This study during 2015-2016 
growing season was done in the research farm of Jihad ministry located in Lalezar village, Bardsir region of Kerman province, Iran. This research was done as split plot experiment in randomized complete block design. Experimental treatments including the irrigation cut-off time (conventional time (5 May), 15 days before the conventional time (20 April) and 15 days after conventional time (20 May)) as the main factor and different sources of fertilizer (cow manure $40 \mathrm{t}_{\text {. ha }}^{-1}$, hen manure15 t. ha ${ }^{-1}$, vermicompost $10 \mathrm{t}$. ha ${ }^{-1}$, humic acid $2 \mathrm{~kg}$. ha ${ }^{-1}$, and chemical fertilizer containing $200 \mathrm{~kg}$. ha ${ }^{-1}$ urea and $140 \mathrm{~kg}$. ha ${ }^{-1}$ phosphorus and potassium) were as sub factors. The results of variance analysis indicate that the influence of irrigation cut-off treatment was significant on the quantitative characteristics of flower, but the qualitative characteristics were not affected by this treatment. The results indicated that delay in irrigation interruption leads to a significant reduction in quantitative traits. So that, the most flowers number $\left(41.10 \mathrm{in} \mathrm{m}^{-2}\right)$, fresh weight of flower, $\left(145.16 \mathrm{~kg} \mathrm{ha}^{-1}\right)$, dry weight of flower $\left(19.41 \mathrm{~kg}\right.$. ha $\left.{ }^{-1}\right)$, fresh weight of stigma $\left(11.12 \mathrm{~kg}\right.$. ha- $\left.{ }^{-1}\right)$ and dry weight of stigma $\left(2.02 \mathrm{~kg}\right.$. ha $\left.{ }^{-1}\right)$ were obtained in the earlier irrigation cut-off treatment (Before the usual time). Investigation of the effect of fertilizer sources on all studied traits showed that this effect was significant in all cases and was not significant only for the values of picrocrocin and safranal. Vermicompost fertilizers and cow manure significantly produced more than other fertilizer treatments flowering and stigma yield in all irrigation treatments. The yield amount of dry stigma was in the treatments of chemical fertilizer $\left(1.91 \mathrm{~kg}^{-\mathrm{ha}^{-1}}\right)$, hen manure $\left(1.57 \mathrm{~kg}\right.$. ha $\left.\mathrm{a}^{-1}\right)$, humic acid $\left(1.42 \mathrm{~kg}\right.$. ha- $\left.{ }^{-1}\right)$ control $\left(1.26 \mathrm{~kg}\right.$. ha $\left.{ }^{-1}\right)$. The yield of dry stigma was significantly higher in the treatments of chemical fertilizer, hen manure and humic acid compared to the control treatment. The highest amount (169.7 $\mathrm{nm})$ of crocin was observed in control treatment and the lowest amount of crocin $(163.1 \mathrm{~nm})$ was obtained in vermicompost treatment. In general, the results indicated that the cessation of irrigation in early April and the use of vermicompost organic fertilizer were the best situations for saffron cultivation in Bardsir area of Kerman province. Some research has shown that irrigation water use in some cases has a negative effect on the yield of saffron. Fallahi and Mahmoodi (2018) investigated the influence of organic and chemical fertilization on growth and flowering of saffron under two irrigation regimes. In this study, the effect of irrigation regime (two-week irrigation period, four-week irrigation period) regardless of amount of rainfall equivalent to consumption of $3600 \mathrm{~m}^{3} / \mathrm{ha}$ (common irrigation treatment in semi-arid regions) and $7200 \mathrm{~m}^{3} / \mathrm{ha}$ (extensive-irrigation treatment), respectively, during saffron growing season was investigated on some physiological indices of growth, corms and flower production in this plant. Also, the consumption effect of organic fertilizers ( 30 ton/ha cow manure based on soil analysis results) and chemical fertilizers $(220,150$ and $100 \mathrm{~kg} / \mathrm{ha}$ of urea, triple super phosphate and potassium sulfate, respectively, based on fertilizer recommendations from soil analysis results) along with control treatment (no fertilizer consumption) on some physiological indices of growth, corms and flower production in Saffron plant were investigated. The experiment was performed as a factorial based on a randomized complete block design with three replications in the research farm of Sarayan Faculty of Agriculture affiliated to Birjand University, Iran, during the 2015-2016 growing year. Vegetative growth indices were determined during the first cycle of plant growth from autumn 2015 to mid-spring 2016 and flowering traits were evaluated in autumn 2016. Total plant biomass increased in all treatments at the first stage of growing season. In both irrigation regimes under the conditions of organic fertilizer consumption prior to planting, total biomass in the last two growth months was higher than other treatments. The crop growth rate in the first 90 days (at the beginning of growth) was less than 3.9 g.m. $\mathrm{m}^{-2}$.day ${ }^{-1}$, can be said that the growth rate of saffron is slow. Crop growth rates at mid (90 to 150 days) and late (150 to 180 days) saffron growth period were fast (3.912 g.m $\mathrm{m}^{-2}$.day ${ }^{-1}$ ) and intermediate (about $5.5 \mathrm{~g} \cdot \mathrm{m}^{-2} \cdot \mathrm{day}^{-1}$ ), respectively. The highest Crop growth rate was observed at about $12 \mathrm{~g} . \mathrm{m}^{-2}$.day ${ }^{-1}$, in conditions of organic fertilizer consumption and 145 days after the first autumn irrigation. Leaf weight ratio (leaf weight to total plant weight including leaf, pod and corms) also decreased in all treatments from about two months after the first autumn irrigation to the end of the growing season and it showed relatively higher values in conditions of nutrient consumption. Organic fertilizer consumption increased $15 \%$ corms number and $13 \%$ of total corms weight per plant compared to control treatment. The highest average weight of replacement corms was obtained with $6.4 \mathrm{~g}$ in the two-week irrigation period and organic fertilizer consumption. The highest number of flowers ( 98 flowers per square meter), flower yield (24.3 grams per square meter), stigma + style yield ( 0.56 grams per square meter) and dry petals yield (3.7 grams per square meter) in cow manure consumption treatment was observed in the four-week irrigation period. In the control and organic fertilizer treatments, the highest flower and stigma yield was observed in the fourweek irrigation period, but in chemical fertilizer treatment highest flower and stigma yield was obtained in the two-week irrigation period. Since, at least in the first year of planting it appears that plant density and transpiration level of saffron are low, consuming $3600 \mathrm{~m}^{3} /$ ha of water during the growing season combined with organic fertilizer can beneficial. Hosseini and Rahimi (2018) investigated the effect of moisture stress on yield and qualitative indices of saffron. This study was conducted in the research farm of Agriculture and Natural Resources Research and Education Center of Gonabad county in 2012 and 2013. This experiment was done as a randomized complete block design with five treatments ( $70 \%$ field capacity, $60 \%$ field capacity, $50 \%$ field capacity, $\mathrm{C}_{1}$ and $\mathrm{C}_{2}$ ) and 4 replications. The quantitative traits studied covering flower number, flower fresh weight, stigma dry weight, number of sister corms at the end of the period, corm weight at the end of the period, 
amount of corm haulm and leaf dry weight, and qualitative characteristics also included the measurement of picrocrocin, crocin and safranal. The results indicated that with increasing the moisture stress, the quantitative characteristics of saffron decreased and its qualitative traits improved. With increasing drought process, quantitative characteristics decreased, which have been frequently reported in other crop plants. On the other hand, the increase in moisture stress is associated with the accumulation of active ingredients in plants, emphasizing the negative correlation between quantitative and qualitative characteristics, and the number and weight of corms has decreased with increasing moisture stress. The number of flowers per unit area $\left(1 \mathrm{~m}^{2}\right)$ in field capacity was $70 \%$ more than other treatments. Dry weight of saffron which is the selfsame as economical saffron was as well as more than other treatments in field capacity $70 \%$, but it did not show significant difference with the four times treatment of irrigation. In the treatment $70 \%$ maximum traits indicated supremacy comparative to other treatments but was not significant and as four times of irrigation seems more reasonable it is recommended to saffron farmers. Four times of irrigation is the native custom from the former that was completed with an extra irrigation in mid-August, which will have a positive impact on the yield of saffron will be useful.

Table 3-Amounts of reference plant evapotranspiration in the study period for different stations (mm/month)

\begin{tabular}{|l|l|l|l|l|l|l|l|l|}
\hline Station name & October & November & December & January & February & March & April & May \\
\hline Kermanshah & 65.13 & 47.83 & 24.31 & 27.14 & 33 & 57.60 & 82.54 & 110.11 \\
\hline Kangavar & 47.37 & 52.83 & 24.10 & 22.14 & 30.88 & 46.40 & 56.12 & 67.22 \\
\hline Ravansar & 66.87 & 54.78 & 36.03 & 38.10 & 48.68 & 73.80 & 82.17 & 111.32 \\
\hline Sarpol-e Zahab & 70.5 & 41.41 & 34.62 & 39.40 & 37.50 & 60.00 & 87.59 & 116.11 \\
\hline Eslamabad-e-Gharb & 63.87 & 58.91 & 32.44 & 34.40 & 41.18 & 63.20 & 81.29 & 110.11 \\
\hline Sonqor & 66 & 41.74 & 23.38 & 20.39 & 32.94 & 57.60 & 83.71 & 111.89 \\
\hline Sanandaj & 63.87 & 43.91 & 23.08 & 20.39 & 30.62 & 53.40 & 81.29 & 111 \\
\hline Khorramabad & 69.63 & 51.74 & 41.41 & 33.10 & 42.35 & 69.60 & 85.83 & 114 \\
\hline Ilam & 69.63 & 66.96 & 42.31 & 54.40 & 51.18 & 70.60 & 85.83 & 114 \\
\hline Hamedan & 63.32 & 35.09 & 22.19 & 19.50 & 29.69 & 53.10 & 81.29 & 110.68 \\
\hline Qorveh & 63 & 37.17 & 21.88 & 19.50 & 29.69 & 51.30 & 79.54 & 108 \\
\hline
\end{tabular}

Table 4-Amounts of effective rainfall in the study period for different stations ( $\mathrm{mm} / \mathrm{month})$

\begin{tabular}{|l|l|l|l|l|l|l|l|l|}
\hline Station name & October & November & December & January & February & March & April & May \\
\hline Kermanshah & 5.2 & 22 & 18.9 & 22.8 & 21.2 & 28.8 & 20 & 2.9 \\
\hline Kangavar & 2.4 & 24.3 & 18.8 & 18.6 & 21 & 23.2 & 20.8 & 4.8 \\
\hline Ravansar & 6.8 & 25.2 & 28.1 & 32 & 33.1 & 36.9 & 29.4 & 6 \\
\hline Sarpol-e Zahab & 1.2 & 17.7 & 27 & 33.1 & 19.8 & 27.7 & 20.7 & 0 \\
\hline Eslamabad-e-Gharb & 3.9 & 27.1 & 25.3 & 28.9 & 28 & 31.6 & 21.6 & 1.5 \\
\hline Sonqor & 9 & 19.2 & 9 & 10.8 & 22.4 & 17.9 & 31.5 & 2.3 \\
\hline Sanandaj & 4.3 & 20.2 & 18 & 16.6 & 18.4 & 24 & 26.6 & 6.7 \\
\hline Khorramabad & 4.1 & 23.8 & 32.3 & 27.8 & 28.8 & 34.8 & 27.3 & 1.2 \\
\hline Ilam & 2.7 & 30.8 & 33 & 45.7 & 34.8 & 35.3 & 26.2 & 0.6 \\
\hline Hamedan & 1 & 14.5 & 12.8 & 9 & 13 & 18.6 & 16.9 & 3.7 \\
\hline Qorveh & 1.7 & 17.1 & 10.2 & 9.5 & 12.6 & 22.4 & 23.4 & 8.7 \\
\hline
\end{tabular}


Table 5-Amounts of saffron water requirement during growing season for different stations ( $\mathrm{mm} / \mathrm{month})$

\begin{tabular}{|l|l|l|l|l|l|l|l|l|}
\hline Station name & October & November & December & January & February & March & April & May \\
\hline Kermanshah & 24.75 & 22 & 18.96 & 22.8 & 22.44 & 28.8 & 33.84 & 40.74 \\
\hline Kangavar & 18 & 24.3 & 18.8 & 18.6 & 21 & 23.2 & 23.01 & 24.87 \\
\hline Ravansar & 25.41 & 25.2 & 28.1 & 32 & 33.1 & 36.9 & 33.69 & 41.19 \\
\hline Sarpol-e Zahab & 26.79 & 19.05 & 27 & 33.1 & 25.5 & 30 & 35.91 & 42.96 \\
\hline Eslamabad-e-Gharb & 24.27 & 27.1 & 25.3 & 28.9 & 28 & 31.6 & 33.33 & 40.74 \\
\hline Sonqor & 25.08 & 19.2 & 18.24 & 17.13 & 22.4 & 28.8 & 34.32 & 41.4 \\
\hline Sanandaj & 24.27 & 20.2 & 18 & 17.13 & 20.82 & 26.7 & 33.33 & 41.07 \\
\hline Khorramabad & 26.46 & 23.8 & 32.3 & 27.8 & 28.8 & 34.8 & 35.19 & 42.18 \\
\hline Ilam & 26.46 & 30.8 & 33 & 45.7 & 34.8 & 35.3 & 35.19 & 42.18 \\
\hline Hamedan & 24.06 & 16.14 & 17.31 & 16.38 & 20.19 & 26.55 & 33.33 & 40.95 \\
\hline Qorveh & 23.94 & 17.1 & 17.07 & 16.38 & 20.19 & 25.65 & 32.61 & 39.96 \\
\hline
\end{tabular}

Table 6-Amounts of saffron irrigation requirement during growing season for different stations (mm/month)

\begin{tabular}{|l|l|l|l|l|l|l|l|l|}
\hline Station name & October & November & December & January & February & March & April & May \\
\hline Kermanshah & 19.55 & 0 & 0.06 & 0 & 1.24 & 0 & 13.84 & 37.84 \\
\hline Kangavar & 15.6 & 0 & 0 & 0 & 0 & 0 & 2.21 & 20.07 \\
\hline Ravansar & 18.61 & 0 & 0 & 0 & 0 & 0 & 4.29 & 35.19 \\
\hline Sarpol-e Zahab & 25.59 & 1.35 & 0 & 0 & 5.7 & 2.3 & 15.21 & 42.96 \\
\hline Eslamabad-e-Gharb & 20.37 & 0 & 0 & 0 & 0 & 0 & 11.73 & 39.24 \\
\hline Sonqor & 16.08 & 0 & 9.24 & 6.33 & 0 & 10.9 & 2.82 & 39.1 \\
\hline Sanandaj & 19.97 & 0 & 0 & 0.53 & 2.42 & 2.7 & 6.73 & 34.37 \\
\hline Khorramabad & 22.36 & 0 & 0 & 0 & 0 & 0 & 7.89 & 40.98 \\
\hline Ilam & 23.76 & 0 & 0 & 0 & 0 & 0 & 8.99 & 41.58 \\
\hline Hamedan & 23.06 & 1.64 & 4.51 & 7.38 & 7.19 & 7.95 & 16.43 & 37.25 \\
\hline Qorveh & 22.24 & 0 & 6.87 & 6.88 & 7.59 & 3.25 & 9.21 & 31.26 \\
\hline
\end{tabular}

Table 7- Amounts of effective rainfall, saffron water and irrigation requirement during growing season for different stations (mm)

\begin{tabular}{|l|l|l|l|}
\hline Station name & water requirement & Effective rainfall & Irrigation requirement \\
\hline Kermanshah & 211.43 & 138.9 & 72.53 \\
\hline Kangavar & 166.98 & 129.1 & 37.88 \\
\hline Ravansar & 249.59 & 191.5 & 58.09 \\
\hline Sarpol-e Zahab & 240.31 & 147.2 & 93.11 \\
\hline Eslamabad-e-Gharb & 237.74 & 166.4 & 71.34 \\
\hline Sonqor & 204.27 & 119.8 & 84.47 \\
\hline Sanandaj & 194.82 & 128.1 & 66.72 \\
\hline Khorramabad & 250.13 & 178.9 & 71.23 \\
\hline Ilam & 282.83 & 208.5 & 74.33 \\
\hline Hamedan & 191.21 & 85.8 & 105.41 \\
\hline Qorveh & 184.2 & 96.9 & 87.3 \\
\hline
\end{tabular}


Knowledge of the spatial variability of saffron water requirement is of great importance in many agricultural activities. Spatial interpolation methods need to be used to estimate saffron water requirement data in Kermanshah province as a whole. So far, many studies have investigated the spatial and temporal distribution of water requirements of different plants. Baladi et al (2017) evaluated the spatial and temporal distribution of maize water requirement using geostatistical methods in Khuzestan province, Iran. In this study, water requirement of maize was estimated by Blaney-Criddle equation and geostatistical methods were used for zoning of maize water requirement. The zoning was done using ARC GIS 10.3 software. First, the data were normalized. Then, with respect to the minimum RMSE value, the appropriate semi variogram and zoning model were selected. The results showed that the simple kriging method with the circular semi-circular model is a desirable model for all months. The RMSE values of this model for March, April, May, and June was obtained $0.08,0.17,0.46$ and 0.48 , respectively. The water requirement zoning results showed that the southern areas of the province had a higher water requirement than the northern regions, and water requirement of the final months were higher than the initial months. At the study term (March to June) the monthly water requirements were 1.98, 5.52, 11.78 and 11.97 ( $\mathrm{mm} /$ day), respectively. Low values of RMSE zoning methods indicate the favorable of water requirement zoning. Kamali (2018) investigated the spatial distribution of Soybean water requirement in Mazandaran. In this research, the required information containing weather, crop features and study region in GIS environment was organized. Reference plant evapotranspiration was calculated by using FAO Penman-Monteith equation and weather data of 51 meteorological stations. The 10-day soybean water requirement was computed by specifying crop coefficient $(\mathrm{kc})$ of soybean in the different growth stages. After performing trend analysis and anisotropy, the behavioral function of the data was determined by computing the experimental semivariogram and fitting the semivariogram models. Interpolation of data was performed using various geostatistical and deterministic methods. The interpolation error was obtained by using the indices Root mean square error (RMSE) and Root Mean Square Standardized Error (RMSSE) of the cross validation method. Maps showed that the maximum amount of water requirement for soybeans occurred in August, ranging from 4.45-5.26 mm/day. The total amount of soybean water requirement in Mazandaran province was obtained from 511 to $613 \mathrm{~mm}$. The total amount of soybean water requirement in the western regions of Mazandaran province was obtained from 511 to $560 \mathrm{~mm}$. The total amount of soybean water requirement in the eastern coastal regions of Mazandaran province was obtained from 560 to $580 \mathrm{~mm}$. The total amount of soybean water requirement in the eastern central regions of Mazandaran province was obtained from 580 to $595 \mathrm{~mm}$. Total soybean water requirement was obtained 595 to $613 \mathrm{~mm}$ for the eastern south regions of Mazandaran province. Mirmousavi et al (2012) investigated the water requirement of Olive plant in Kermanshah province, Iran. In this study, the methods FAO - Penman-Monteith, Thornthwaite, modified Blaney-Criddle, modified Hargreaves and Penman were used to calculate the monthly and annual water requirement of the reference plant. Comparison of the above five methods with lysimeter data shows that the FAO-Penman-Monteith method estimates the evapotranspiration value of the reference plant more accurately. The zoning of reference plant evapotranspiration and olive water requirement in Kermanshah province was performed by using from FAOPenman-Monteith method extraction data at Kangavar, Ravansar, Kermanshah, Eslamabad-e-Gharb and Sarpol Zahab Stations. The results showed that the lowest and highest monthly and annual water requirements for the reference plant were in Kangavar and Ravansar areas of Kermanshah province, respectively. The monthly and annual evapotranspiration of the reference plant in Kangavar area is 5.8 and $38.4 \mathrm{~mm}$, respectively. The monthly and annual evapotranspiration of the reference plant in Ravansar area is 8.5 and 48.9, respectively. The highest annual water requirement for olives is observed in the Ravansar area of Kermanshah province, which is about $923.3 \mathrm{~mm}$. In this study we used geostatistical interpolation methods in GIS software. Figures 2-9 show maps of the water requirement of saffron in different months in millimeters per day. Maps show that the highest water requirement of saffron is in the west of Kermanshah province and the lowest water requirement is in the east of Kermanshah province. Maps showed that the highest saffron water requirement happened in May which was 0.829-1.432 mm/day. The highest and lowest water requirement of saffron were observed for Sarpol-e Zahab and Kangavar stations, respectively. Figure 10 shows the map of the saffron water requirement throughout the whole growth period in millimeters. This map shows that the saffron water requirement is increasing from east to west. Figure 11 shows the effective rainfall map throughout the whole saffron growth period in millimeters. This map shows that the least effective rainfall is northeast of Kermanshah province. Figure 12 shows the map of the saffron irrigation requirement throughout the whole growth period in millimeters. This map shows that saffron irrigation requirement has the lowest and highest in east and west of Kermanshah province, respectively. 


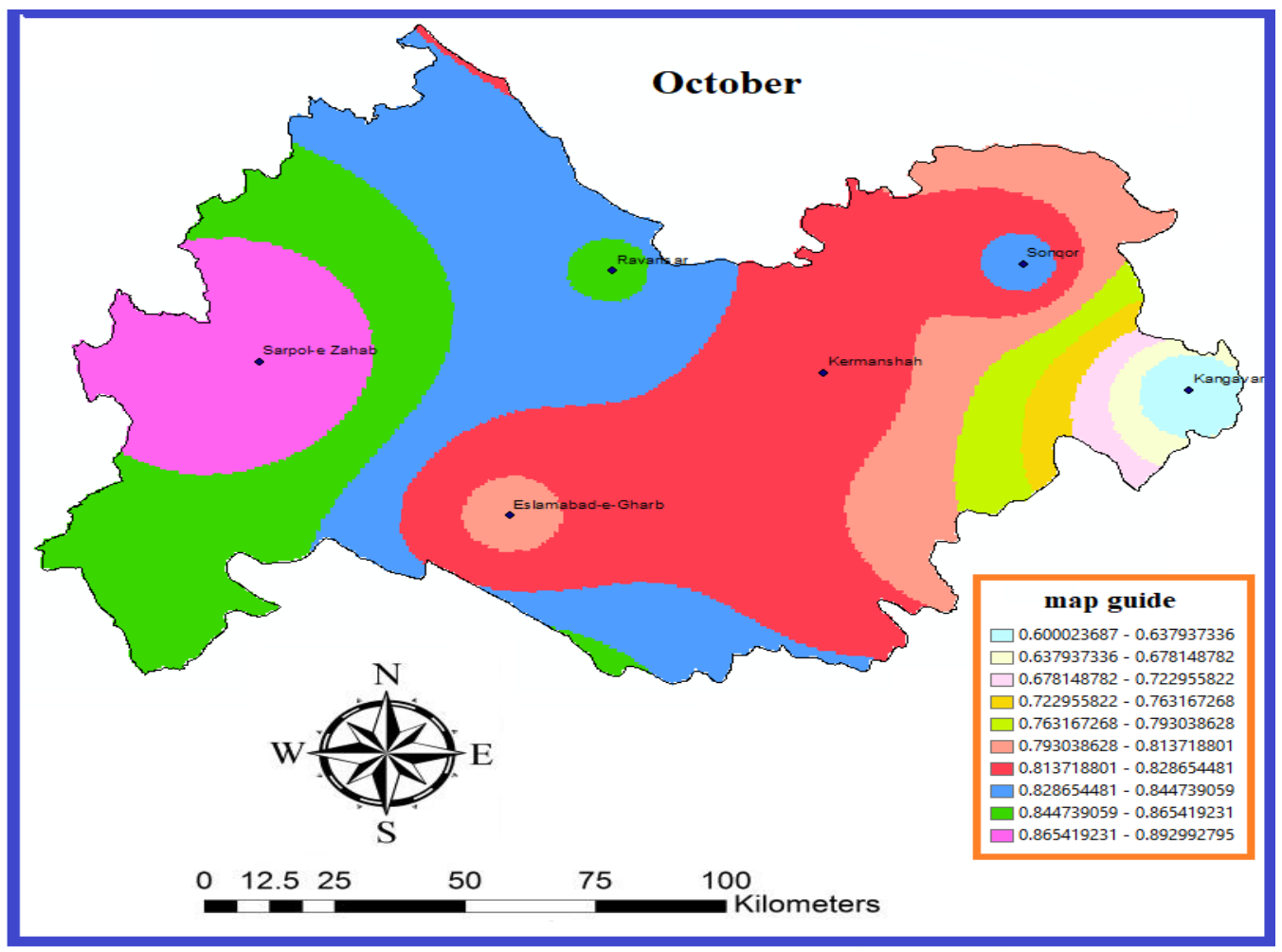

Figure 2-Map of saffron water requirement in October ( $\mathrm{mm} /$ day)

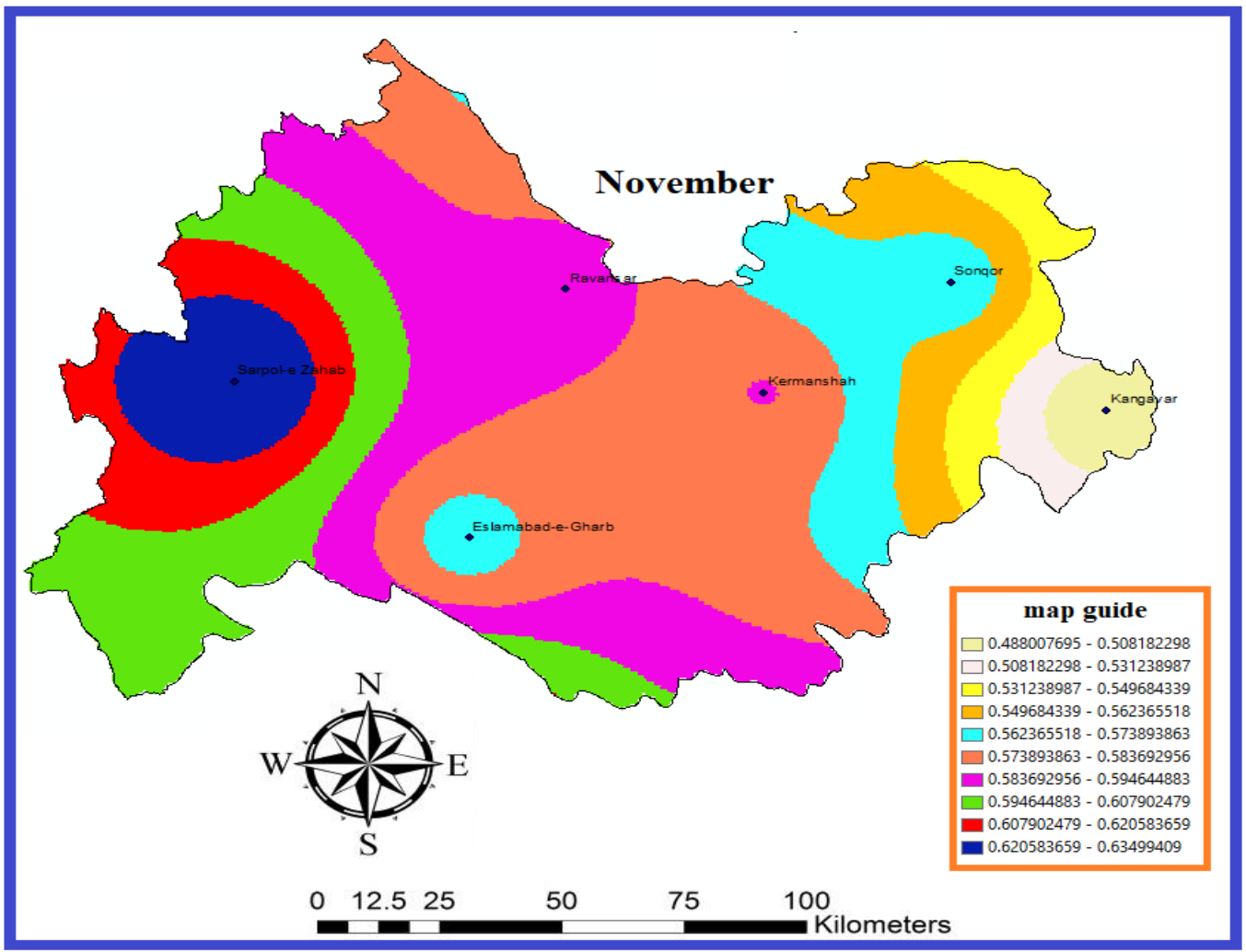

Figure 3-Map of saffron water requirement in November ( $\mathrm{mm} /$ day) 


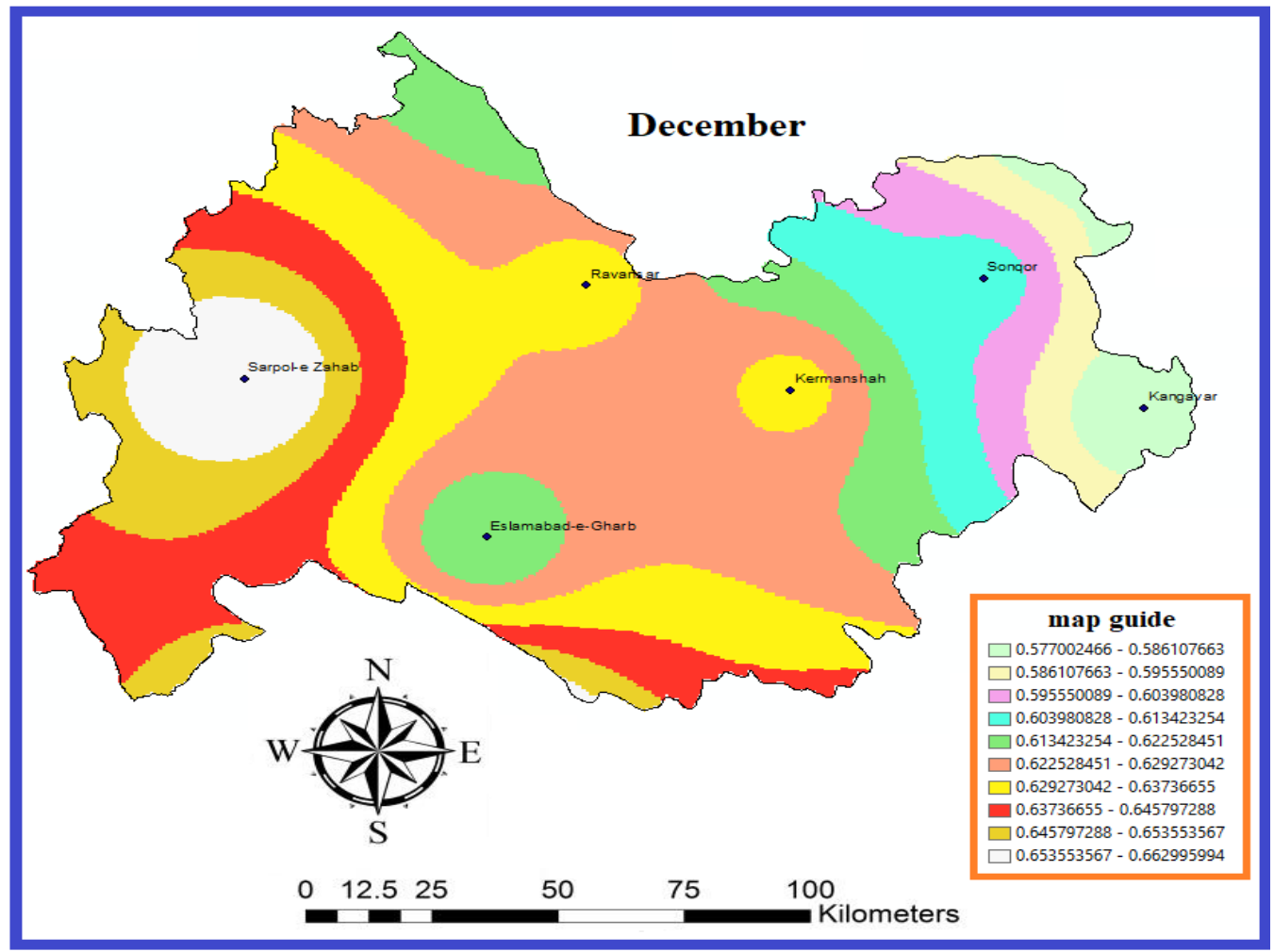

Figure 4-Map of saffron water requirement in December ( $\mathrm{mm} /$ day)

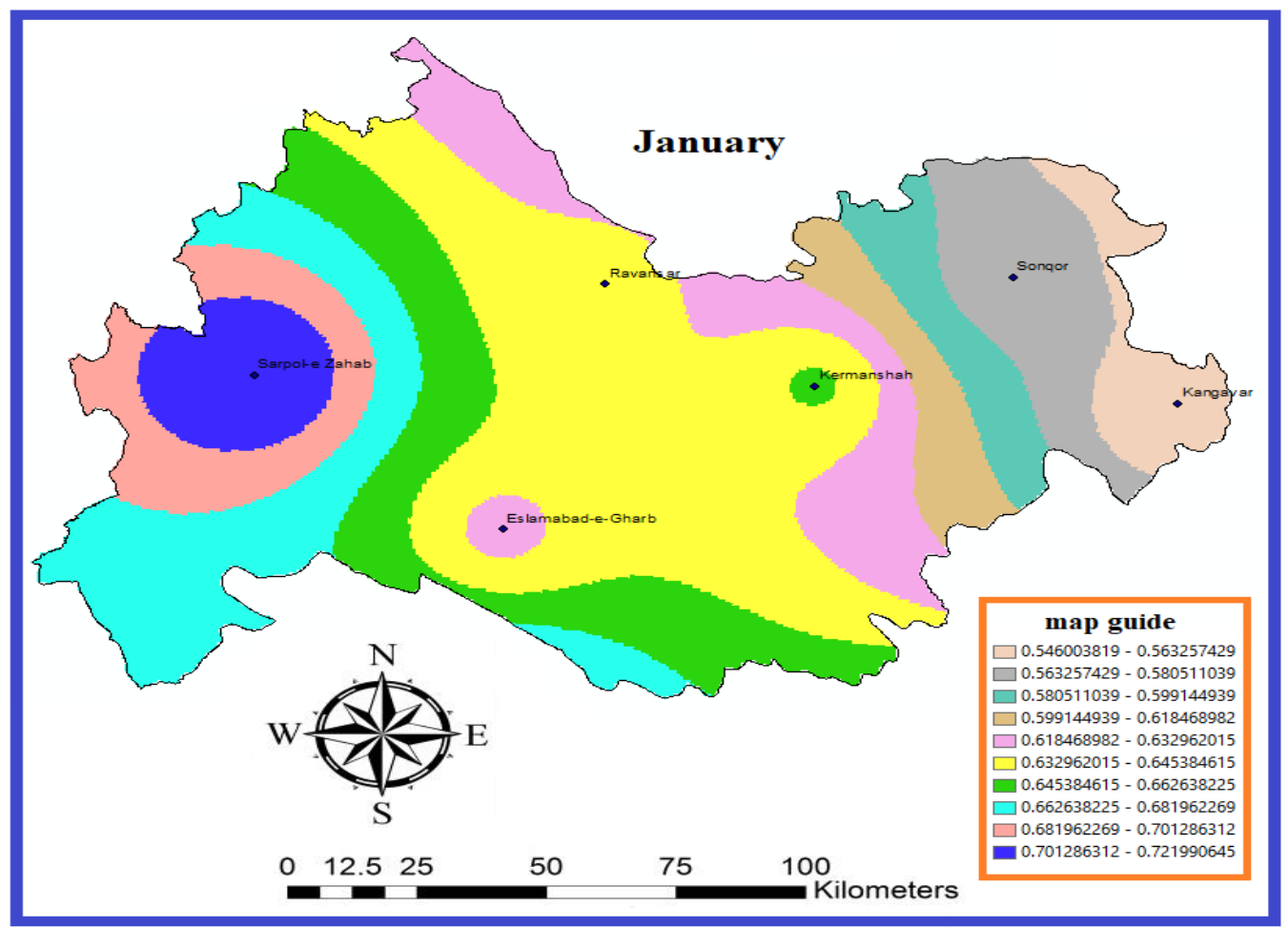

Figure 5-Map of saffron water requirement in January ( $\mathrm{mm} /$ day) 


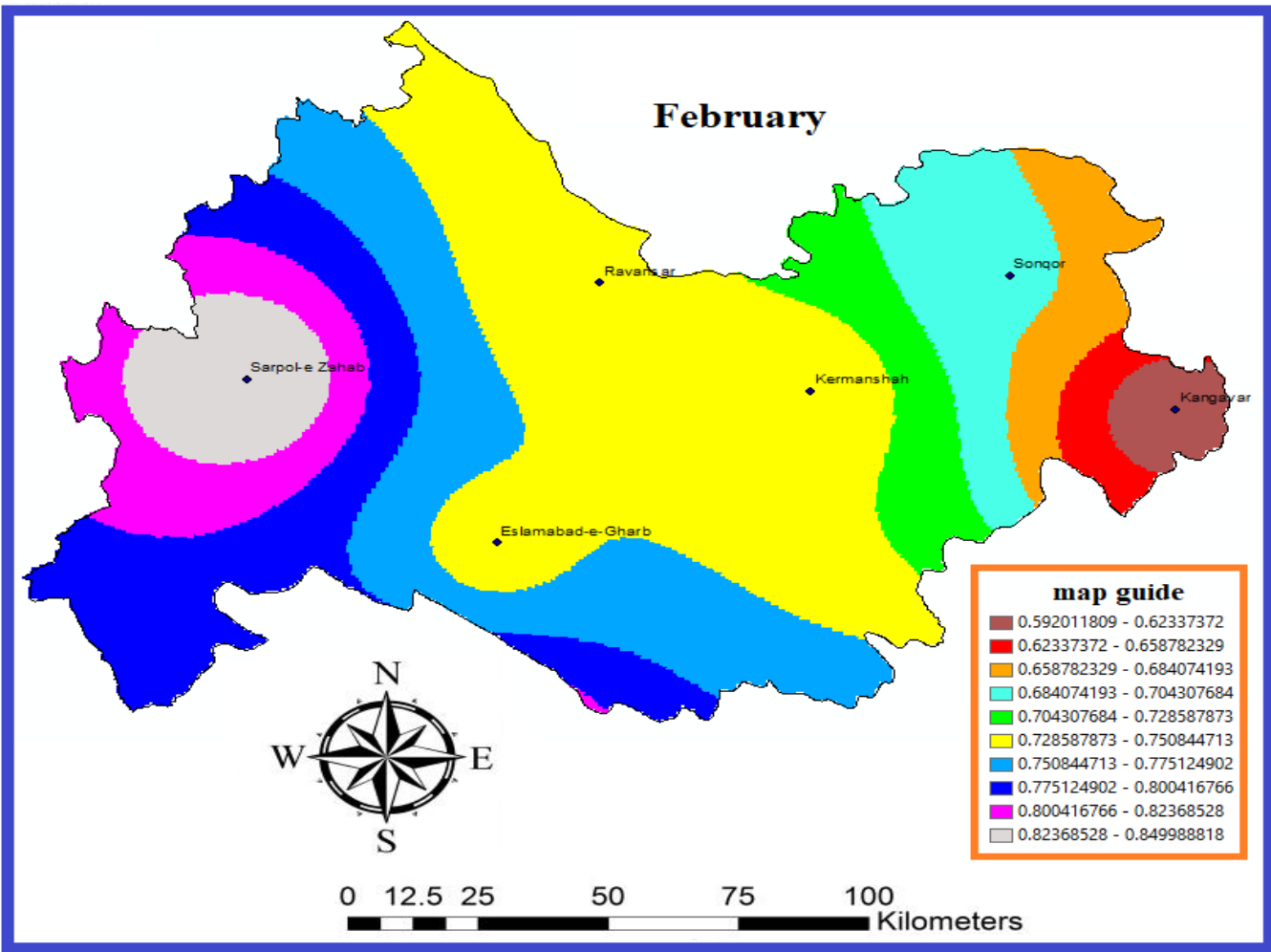

Figure 6-Map of saffron water requirement in February (mm/day)

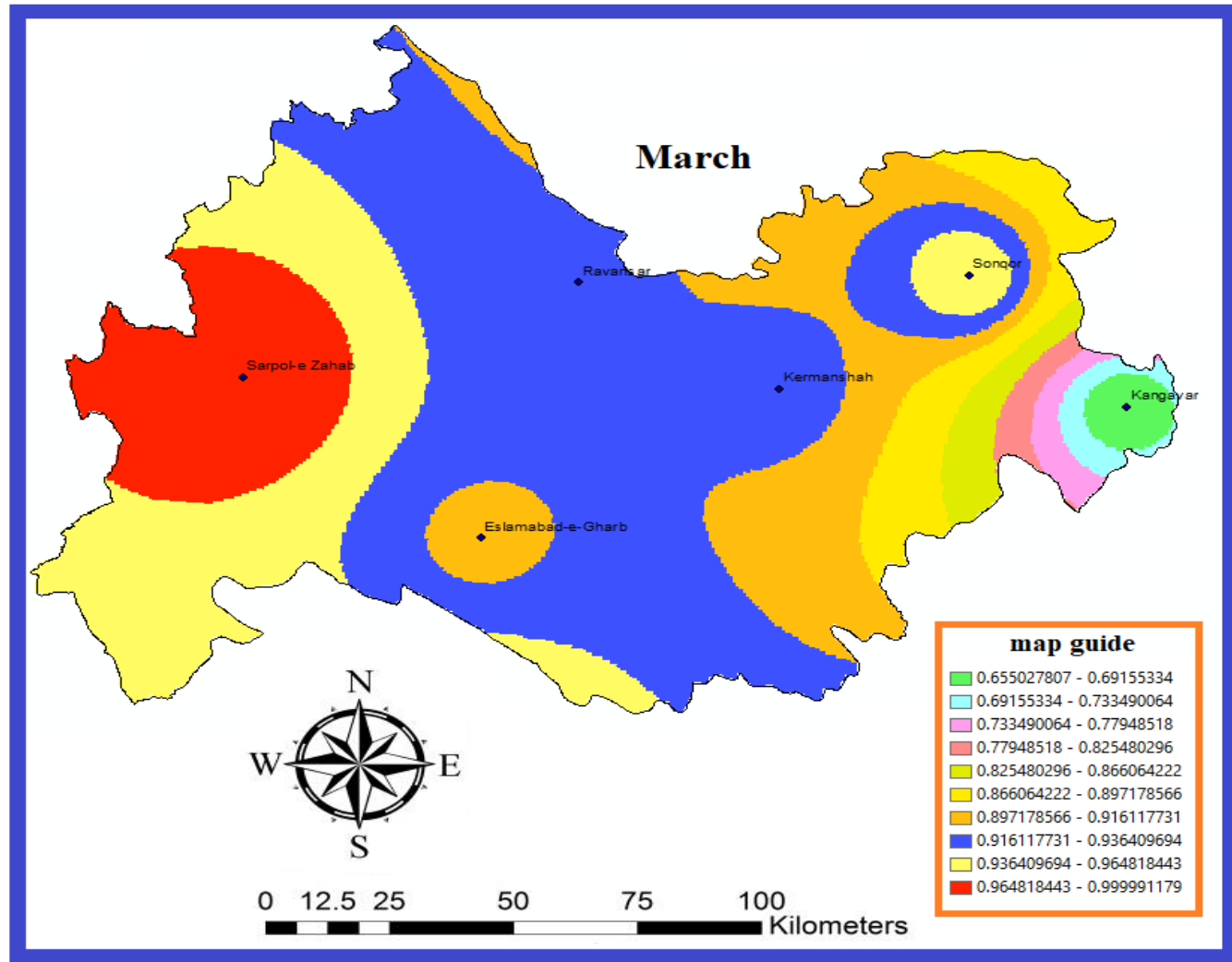

Figure 7-Map of saffron water requirement in March (mm/day) 


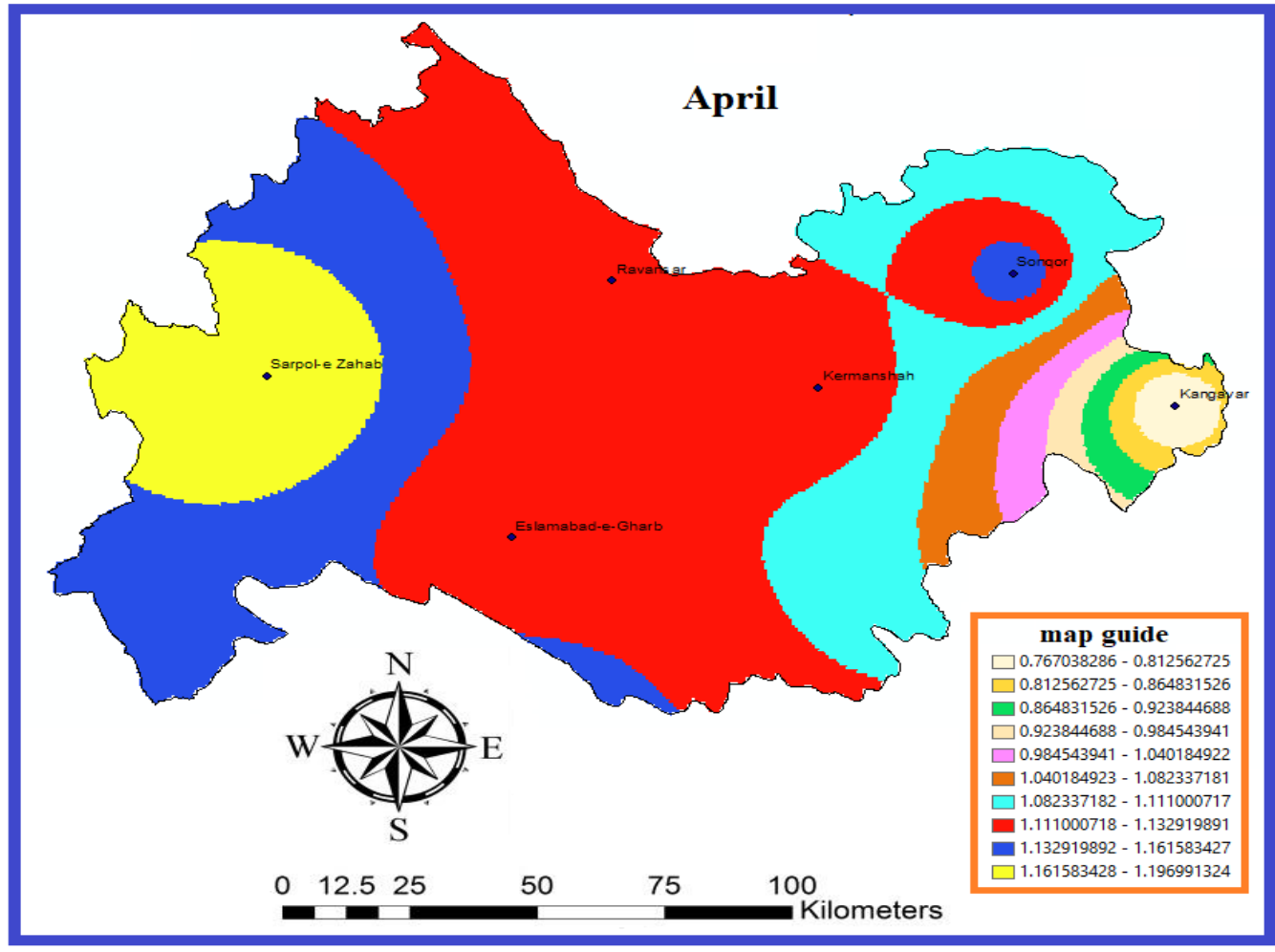

Figure 8-Map of saffron water requirement in April (mm/day)

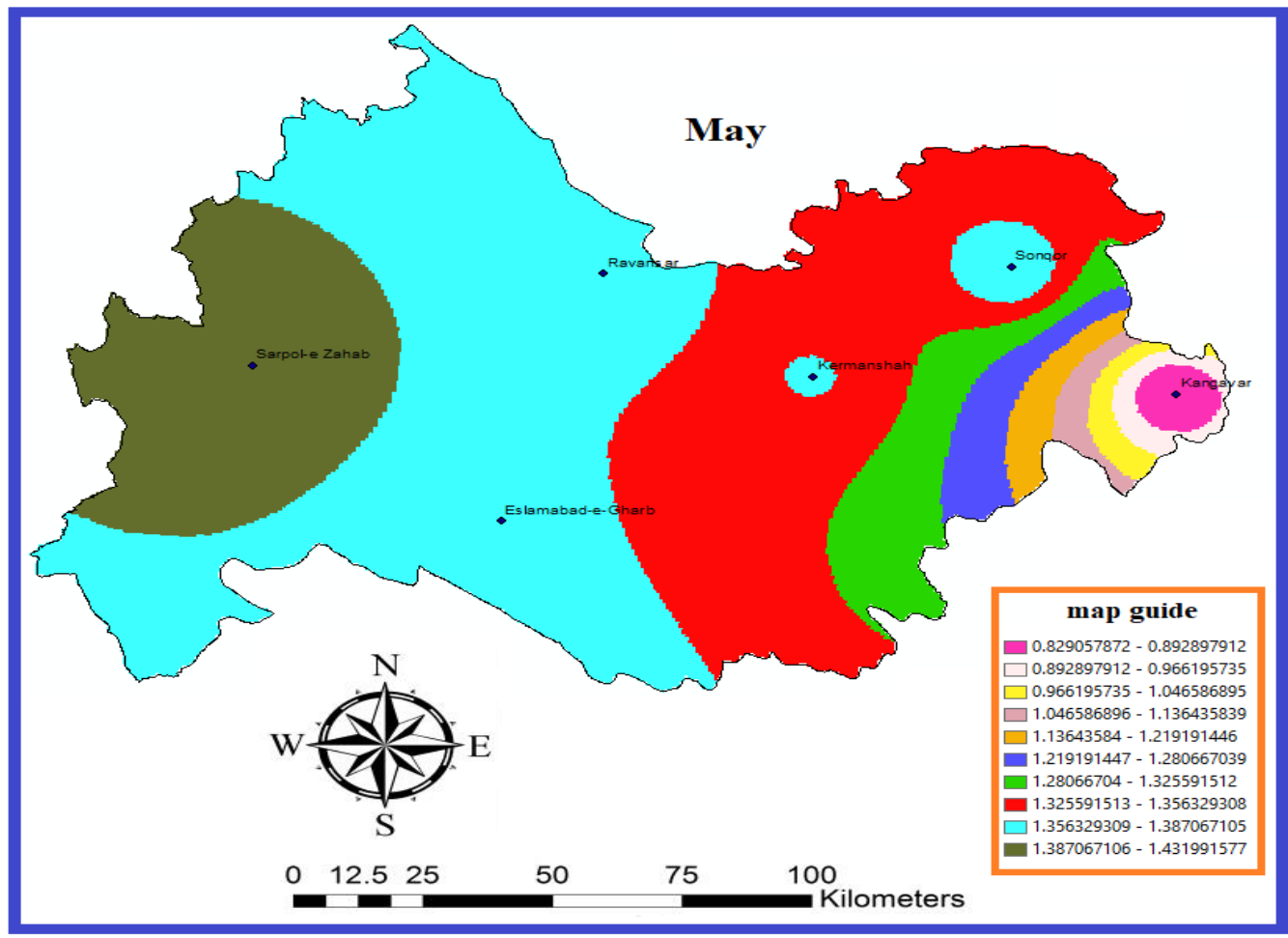

Figure 9-Map of saffron water requirement in May ( $\mathrm{mm} /$ day) 


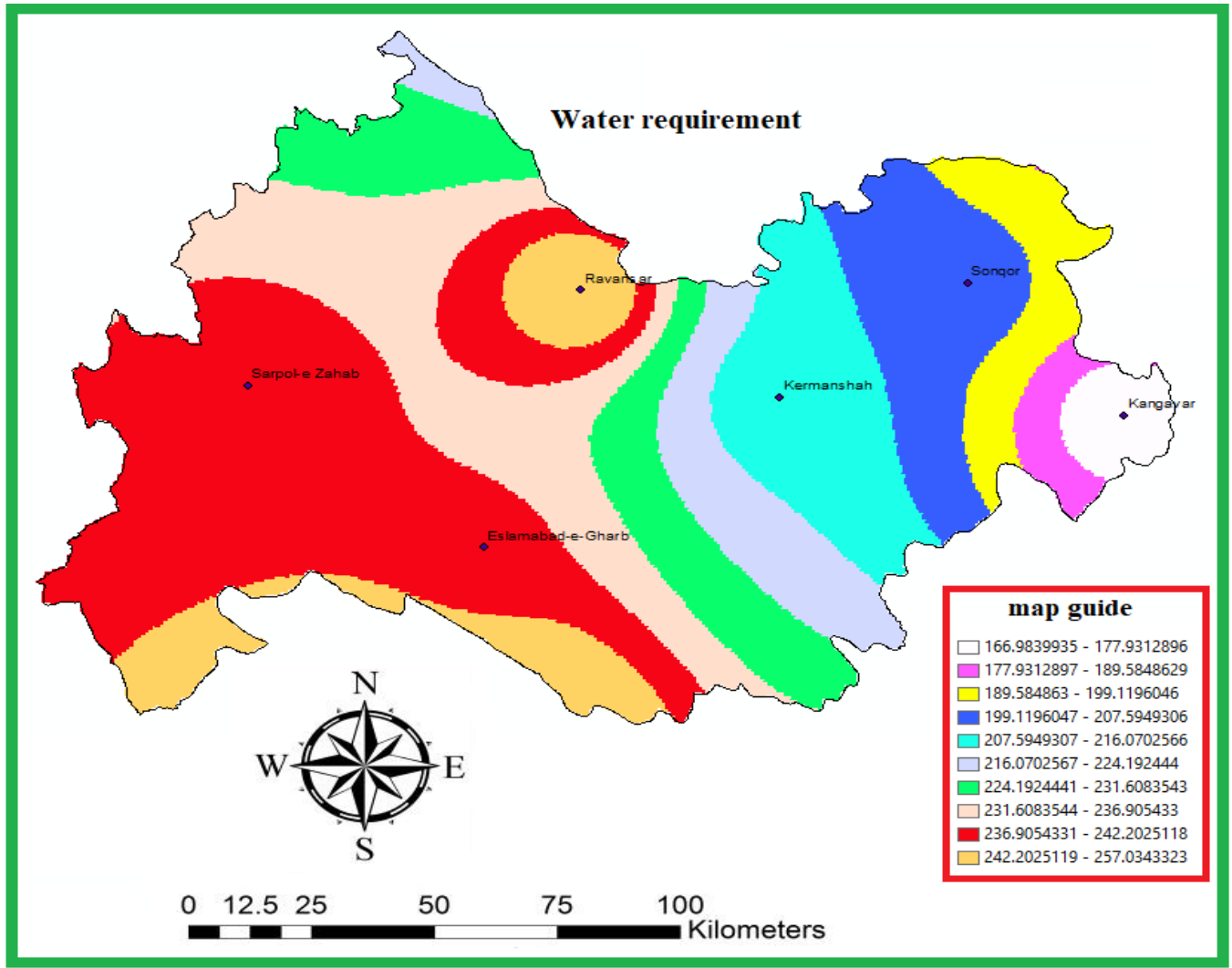

Figure 10-Map of saffron water requirement during growing season (mm)

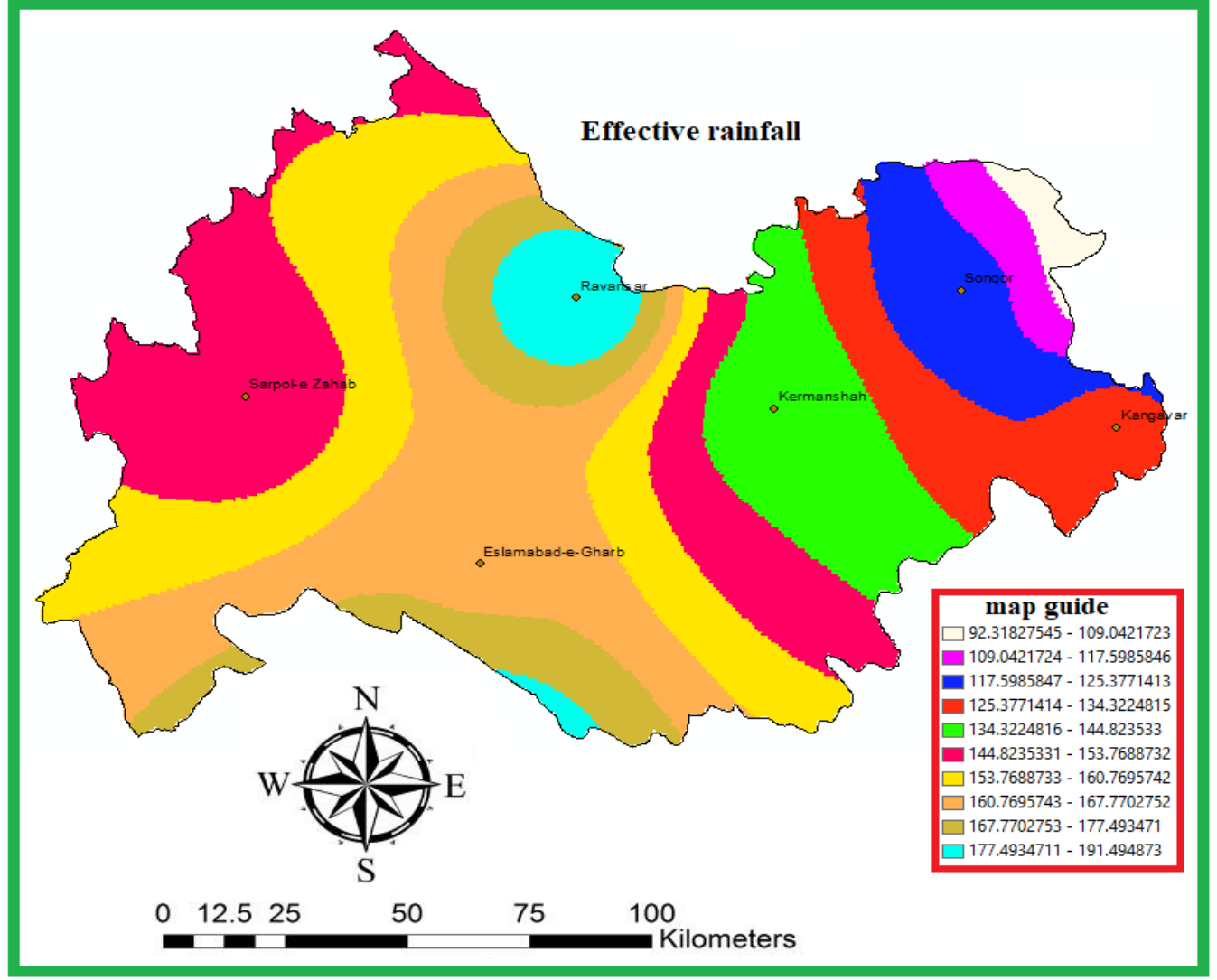

Figure 11-Map of effective rainfall during growing season (mm) 


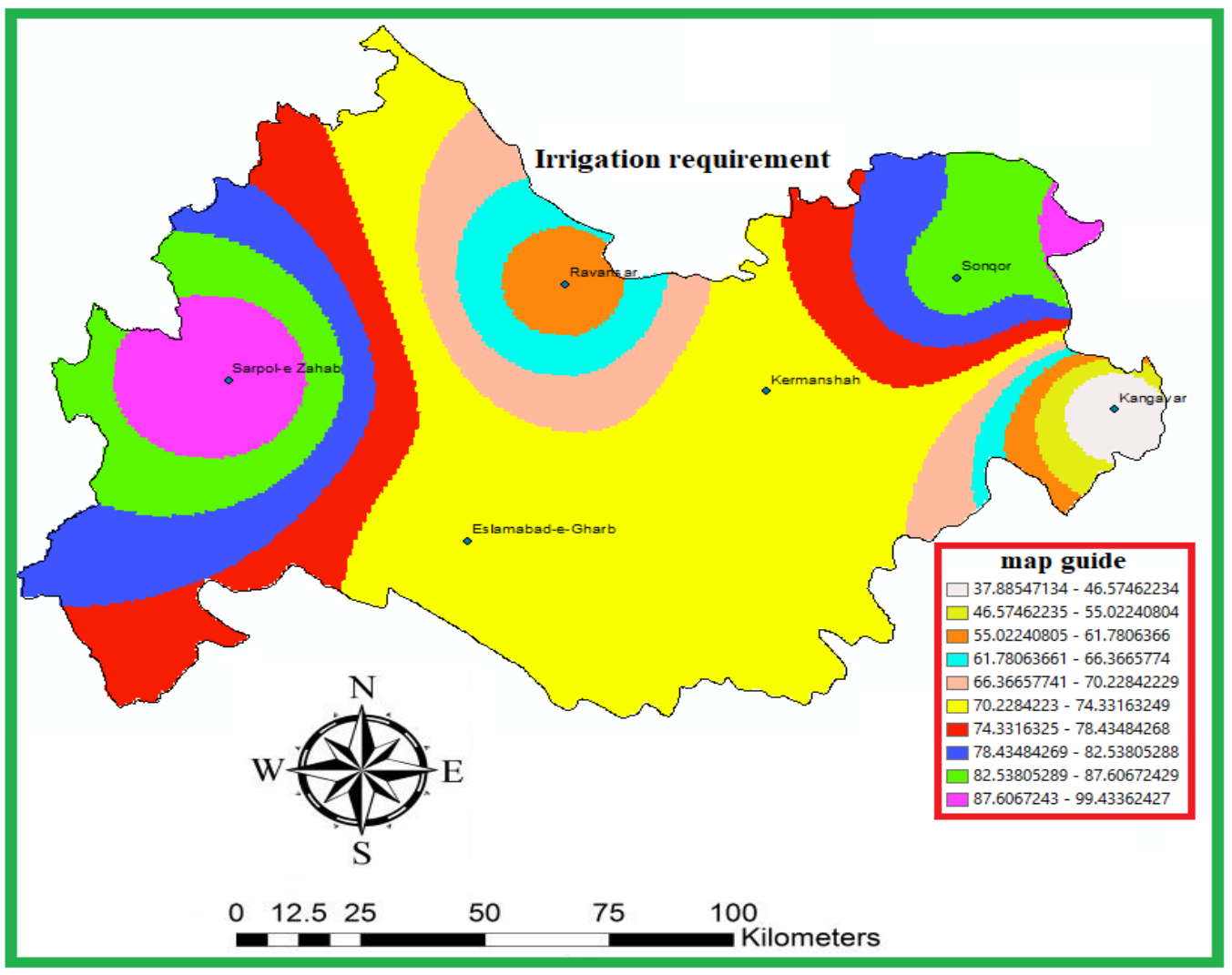

Figure 12-Map of saffron irrigation requirement during growing season $(\mathrm{mm})$

\section{Conclusion}

The high consumption of water in the agricultural sector has caused parts of Iran to become waterless. To optimize water consumption, need to manage water resources. One of the managerial parameters in agricultural planning is determining the water requirement of plants. (Ahmadpari et al, 2019). Saffron as one of the traditional products of Iran and due to its high price in non-petroleum exports of the country, its relative advantage and importance in terms of production. Considering the water crisis in Kermanshah province and the economic value of saffron crops, in recent years, attention has been paid to changing the province's cultivation pattern and replacing this crop with low water requirement. So that, Saffron cultivation has been common in large parts of Kermanshah province. Due to the low water requirement and economic appropriate Profit, its cultivation is extending in Kermanshah province, regardless to the climatic needs of the plant. This reduces the quality and performance of saffron production and make into no proper use of agricultural lands. In this research the water requirement of saffron and the effect of efficient rainfall is studied in Kermanshah province and the amount of supplemental irrigation water was calculated. Water requirement was obtained experimentally and by multiplying crop coefficient of saffron $(\mathrm{KC})$ with evapotranspiration of the reference crop $\left(\mathrm{ET}_{\mathrm{O}}\right)$. To calculate evapotranspiration of the reference crop $\left(\mathrm{ET}_{\mathrm{O}}\right)$ the Penman- Monteith FAO equation was used as the most valid method for estimating water requirement. Amount of effective rainfall was estimated by cropwat model based on USDA method. The results show that water requirement during growing season for saffron is $211.43,166.98$, 249.59, 240.31, 237.74, 204.27, 194.82, 250.13, 282.83, 191.21 and $184.2 \mathrm{~mm}$ for Kermanshah, Kangavar, Ravansar, Sarpol-e Zahab, Eslamabad-e-Gharb, Sonqor, Sanandaj, Khorramabad, Ilam, Hamedan and Qorveh respectively. Also, the results show that amount of effective rainfall during growing season for saffron is 138.9, 129.1, 191.5, 147.2, 166.4, 119.8, 128.1, 178.9, 208.5, 85.8 and 96.9 mm for Kermanshah, Kangavar, Ravansar, Sarpol-e Zahab, Eslamabad-e-Gharb, Sonqor, Sanandaj, Khorramabad, Ilam, Hamedan and Qorveh respectively. Moreover, the results show that irrigation requirement during growing season for saffron is 72.53, 37.88, 58.09, 93.11, 71.34, 84.47, 66.72, 71.23, 74.33, 105.41 and 87.3 mm for Kermanshah, Kangavar, Ravansar, Sarpol-e Zahab, Eslamabad-e-Gharb, Sonqor, Sanandaj, Khorramabad, Ilam, Hamedan and Qorveh respectively. Maps showed that the highest saffron water requirement happened in May which was $0.829-1.432 \mathrm{~mm} / \mathrm{day}$.The highest and lowest water requirement of saffron were observed for Sarpol-e Zahab and Kangavar stations, respectively. Therefore, saffron is a low water consumer plant and highly recommended for water consumption optimization. It can be replaced by the plants with high water consumption. Regular planning and ordered infrastructure can play an important role in the terms of exportation of saffron. Therefore, cultivation is recommended to increase the economic value of water and water management in the agricultural sector. 
Therefore, it is recommended to optimize water consumption in agricultural sector, in addition to determining the exact time of irrigation and its proper amount for saffron crop which can reduce the negative effects of excessive and inopportune time irrigation on the yield of this crop, policies to increase agricultural water use efficiency through the use of deficit irrigation methods should also be included in policy makers' planning (Shirzadi Laskookalayeh et al, 2017).

\section{References}

[1] Ahmad, L., Parvaze, S., Parvaze, S., Kanth, R. H. (2017). Crop water requirement of saffron (Crocus sativus) in Kashmir valley. Journal of agrometeorology, 19(4), 380-381.

[2] Ahmadee, M., Khashei Siuki, A., Sayyari, M.H. (2017). Comparison of efficiency of different equations to estimate the water requirement in Saffron (crocus sativus L.) (case Study: Birjand plain, Iran), Journal of agroecology, 8(4), 505-520.

[3] Ahmadpari, H., Shokoohi, E., Mohammadi Lalabadi, N., Safavi Gerdini, M., Ebrahimi, M. (2019). Assessment of potential evapotranspiration estimation methods in the Fasa region. Specialty journal of agricultural sciences, 5(2), 56-66.

[4] Alavizadeh, S.A.M., Monazzam Esmaeel pour, A., Hosseinzadeh Kermani, M. (2013). Possibility study of areas with potential cultivation of saffron in Kashmar plain using GIS, Saffron agronomy \& technology, 1(1), 71-95.

[5] Aliakbari, P., salari, A., KhasheiSiuki, A. (2018). Determine of the actual and potential evapotranspiration and appropriate model for determining water requirement of saffron (Case study: Torbat Heydarieh). Iranian journal of ecohydrology, 5(3), $1051-1061$.

[6] Babaee, M., Shokat-Naghadeh, A., Ahmadpari, H., Nabi-Jalali, M. (2019). Comparison of different methods with lysimeter measurements in estimation of rice evapotranspiration in Sari Region, Revista Ingenieria UC, 26(2), 175-184.

[7] Baladi, Y., Ezadpanah, Z., Golabi, M., Albaji, M. (2017). Evaluation spatial and temporal distribution of maize water requirement using geostatistical methods in Khuzestan province, Journal of irrigation and water engineering, 7(28), 123-137.

[8] Ebrahimipak, N., Ahmadee, M., Egdernezhad, A., Khashei Suiki, A. (2018). Evaluation of AquaCrop to simulate saffron (crocus sativus 1.) yield under different water management scenarios and zeolite amounts. Journal of soil and water resources conservation, 8(1), 117-132.

[9] Fallahi, H., Mahmoodi, S. (2018). Influence of organic and chemical fertilization on growth and flowering of saffron under two irrigation regimes. Saffron agronomy and technology, 6(2), 147-166.

[10] Farajzadeh, M., Mirzabayati, R. (2007). Possibility study of areas with potential cultivation of saffron in Nishabor plain using GIS, The journal of spatial planning, 11(1), 67-91.

[11] Ghamarnia, H., Soltani, N. (2016). Cultivable area zoning of saffron in Kermanshah province: An option for crop pattern change to cope water scarcity, Land management journal, 4.1(1), 1-11.

[12] Hosseini, M., Rahimi, H. (2018). Effect of moisture stress on yield and qualitative indices of saffron (Crocus sativus L.). Journal of saffron research, 5(2), 247-255.

[13] Kamali, M.I., (2018). Preparation of spatial distribution maps of soybean water requirement in Mazandaran. Iranian journal of irrigation \& drainage, 12(5), 1059-1072.

[14] Karimiferezghi, M., Kafi, M., Nezami, A. (2018). Comparison of the effect of irrigation levels and methods on leaf area and replacement corm production of saffron (Crocus sativus L). Saffron agronomy and technology, 6(3), 279-290.

[15] Koocheki, A., Seyyedi, S. M., Eyni, M. J. (2014). Effect of irrigation levels and high corm density on growth and phosphorus uptake of daughter corms of saffron (Crocus sativus L.). Iranian journal of crop sciences, 16(3), 222-235.

[16] Mirmousavi, H., Panahi, H., Akbari, H., Akbarzadeh, Y. (2012). Calibration methods to estimate reference crop evapotranspiration and calculated potential water requirements of Olive plant in Kermanshah province. Geography and sustainability of environment, 2(3), 45-64.

[17] Muhammad, N. (2009). Simulation of maize crop under irrigated and rainfed conditions with CROPWAT model. Journal of agricultural and biological science, 4(2), 68-73.

[18] Rajabi, Z., Behyar, M B., Ghayoor, H A., Ezatian, V., Gandomkar, A. (2015). Estimation saffron evapotranspiration by Penman Monteith method and its water require in Isfahan province. Geographical researches quarterly journal, 30 (1), $239-252$.

[19] Rezaei, A., Feizi, H., Moradi, R. (2019). Response of quantitative and qualitative characteristics of Saffron flower to the last irrigation cut-off time and various fertilizer resources. Saffron agronomy and technology, 7(1), 3-25.

[20] Shirzadi Laskookalayeh, S., Sabouhi, M., Keikha, A.A., and Davari, K. (2017). Irrigation management of saffron by using the price and quantity policies of water (case study: Naishabur basin). Saffron agronomy \& technology 5(2), 149-160.

[21] Sobhani, B. (2016). Agroclimatic zoning saffron cultivation in Ardabil province using of method AHP, Journal of saffron research, $4(1), 72-86$. 